Document downloaded from:

http://hdl.handle.net/10251/120136

This paper must be cited as:

Díez-Sánchez, E.; Llorca Martínez, ME.; Quiles Chuliá, MD.; Hernando Hernando, MI. (2018). Using different fibers to replace fat in sponge cakes: In vitro starch digestion and physico-structural studies. Food Science and Technology International. 24(6):533-543. https://doi.org/10.1177/1082013218771412

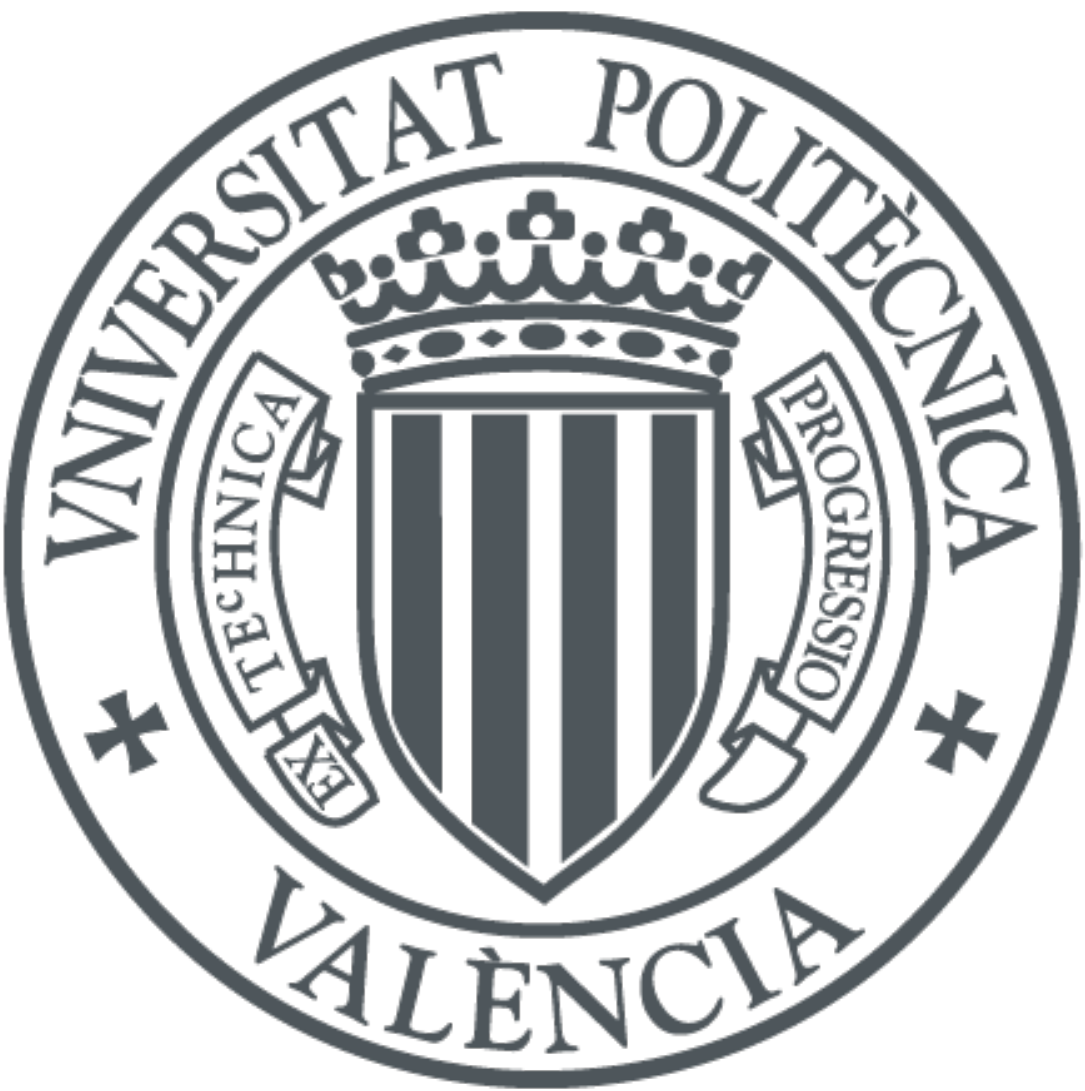

The final publication is available at

http://doi.org/10.1177/1082013218771412

Copyright SAGE Publications

Additional Information 


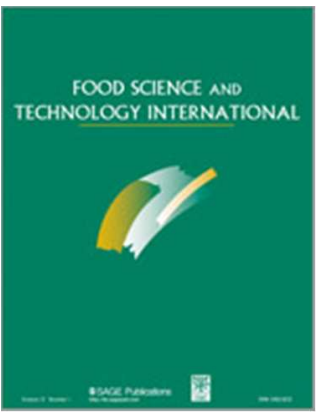

\section{USING DIFFERENT FIBERS TO REPLACE FAT IN SPONGE CAKES. IN VITRO STARCH DIGESTION AND PHYSICO- STRUCTURAL STUDIES}

\begin{tabular}{|c|c|}
\hline Journal: & Food Science and Technology International \\
\hline Manuscript ID & FSTI-18-0029.R1 \\
\hline Manuscript Type: & Research Article \\
\hline Subject category: & Physical, Chemical and Sensory Properties \\
\hline Date Submitted by the Author: & 06-Mar-2018 \\
\hline Complete List of Authors: & $\begin{array}{l}\text { Diez-Sánchez, Elena; Universitat Politecnica de Valencia, Food Technology } \\
\text { Llorca, Empar; Universidad Politecnica de Valencia Escuela Tecnica } \\
\text { Superior del Medio Rural y Enologia, Tecnología de Alimentos } \\
\text { Quiles, Amparo; Universitat Politecnica de Valencia, Food Technology } \\
\text { Hernando Hernando, Maria Isabel; Universidad Politecnica de Valencia, } \\
\text { Food Technology }\end{array}$ \\
\hline Keywords: & Dietary fiber, Freshness quality, Microstructure, Starch, Digestion \\
\hline Abstract: & $\begin{array}{l}\text { This study assessed the effect of substituting } 30 \% \text { of fat by fiber-rich } \\
\text { ingredients in sponge cake quality, structure, acceptability and starch } \\
\text { digestibility. The apparent viscosity of the different formulations was } \\
\text { measured and micro baking was simulated. Texture profile tests were } \\
\text { carried out and the crumb structure was examined. In vitro digestion was } \\
\text { performed to study the digestibility of starch and a sensory test was } \\
\text { carried out to know consumer acceptance. The soluble fiber affected the } \\
\text { structure and quality of the cakes less than the insoluble fiber and the use } \\
\text { of soluble fiber in the formulation resulted in lower glucose release under in } \\
\text { vitro conditions Moreover, the consumer did not found differences among } \\
\text { the control cake and the cakes prepared with soluble fiber. Considering the } \\
\text { results as a whole, soluble fiber may be used for partial replacement of fat } \\
\text { in sponge cake formulations and constitutes an appropriate strategy for } \\
\text { obtaining healthy sponge cakes. }\end{array}$ \\
\hline
\end{tabular}


2

3

4

5

6

7

8

9

10

11

12

13

14

15

16

17

18

19

20

21

22

23

24

25

26

27

28

29

30

31

32

33

34

35

36

37

38

39

40

41

42

43

44

45

46

47

48

49

50

51

52

53

54

55

56

57

58

59

60

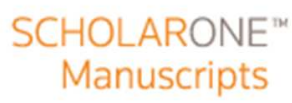

http://mc.manuscriptcentral.com/fsti 
1

2

3

4 Elena Diez-Sánchez, Empar Llorca, Amparo Quiles*, Isabel Hernando

5 Food Microstructure and Chemistry Research Group, Department of Food

6 Technology, Universitat Politècnica de València, Camino de Vera, $s / n$,

7 46022, Valencia, Spain

$8 \quad{ }^{*}$ Corresponding author E-mail address: mquichu@tal.upv.es (A. Quiles)

\section{9}

10

11 


\section{2 \\ ABSTRACT}

14 This study assessed the effect of substituting $30 \%$ of fat by soluble, 15 insoluble fiber, or a mix of both fibers in sponge cake quality, structure, 16 acceptability and starch digestibility. The apparent viscosity of the different

17 formulations was measured and micro baking was simulated. Texture profile 18 tests were carried out and the crumb structure was examined. In vitro 19 digestion was performed to study the digestibility of starch and a sensory test 20 was carried out to know consumer acceptance. The soluble fiber 21 (maltodextrin) affected the structure and quality of the cakes less than the 22 insoluble fiber (potato fiber) and the use of soluble fiber in the formulation 23 resulted in lower glucose release under in vitro conditions Moreover, the 24 consumer did not found differences among the control cake and the cakes 25 prepared with soluble fiber. Considering the results as a whole, soluble fiber 26 may be used for partial replacement of fat in sponge cake formulations and 27 constitutes an appropriate strategy for obtaining healthy sponge cakes.

28 Keywords: sponge cake, fiber, quality, structure, starch digestion 
INTRODUCTION

Sponge cakes are a well-known product worldwide and are deeply rooted

in the culture of each country. They are popular with consumers, who consider them delicious products with particular organoleptic characteristics

35 (Matsakidou et al., 2010).

36 The major ingredients that give sponge cakes their specific properties 37 include not only eggs, flour and sugar but also fat, which comprises approximately $15 \%-25 \%$ of the batter (Rodríguez-García et al., 2012). Fat contributes to air incorporation into the batter in the form of small bubbles,

40 which will improve the stability of the batter minimizing the coalescence 41 phenomena, thus increasing the volume of the cakes; fat also interferes with 42 the continuity of the gluten, favoring the formation of a final product with a 43 smoother, softer texture (Román et al., 2015). Nevertheless, it is the food 44 component with the highest energy value and the high percentage of fat in 45 sponge cakes gives them a high calorie content (Rodríguez-García, 46 Salvador, et al., 2014; Zahn et al., 2010). Many studies have demonstrated 47 the close connection between excessive fat consumption and the 48 development of excess weight, obesity and certain cardiovascular diseases 49 (Kratz et al., 2013; Mente et al., 2009). The World Health Organization 50 (World Health Organization (WHO), n.d.) has warned that excess weight and 51 obesity, considered as a typical problem of high-income countries, are 52 becoming major public health problems in many parts of the world. The 53 United Nations Food and Agriculture Organization (United Nations Food and 
54 Agriculture Organization (FAO), n.d.) also states that good nutrition is the first 55 line of defence against disease and requires special attention on the part of 56 the food industry, starting with food design.

57 Nowadays, the nutritional value of food is becoming increasingly important, 58 as well as the fact that the nutrients contained in them meet the specific 59 needs of the individual. This is in agreement with the call of the WHO and the 60 US Senate Commission on Nutrition's general dietary recommendations to 61 limit the energy intake from total fat and raise the quantity of dietary fiber to a 62 minimum of $22 \mathrm{~g}$ per day. In fact, there is increasing demand from 63 consumers for low-fat, low-calorie, dietary fiber-rich products (Martínez64 Cervera et al., 2012).

65 Dietary fiber is of increasing nutritional and clinical interest owing to its 66 beneficial effects on health and is being used as an ingredient in a large 67 variety of foods (Oh et al., 2014). Fiber can regulate intestinal function, 68 protect the intestinal walls from contact with certain harmful substances, 69 reduce cholesterol absorption and regulate blood glucose levels (Hardacre et 70 al., 2015; Oh et al., 2014). The agreed definition of dietary fiber refers to 71 carbohydrate polymers with ten or more monomeric units, which are not 72 hydrolyzed in the small intestine of humans (Viebke et al., 2014) . Depending 73 on chemical, physical, and functional properties, dietary fiber can be 74 classified into soluble and insoluble fiber. Soluble dietary fiber (SDF) includes 75 pectins, gums, inulin- type fructans and some hemicelluloses whereas 76 insoluble dietary fiber (IDF) includes lignin, cellulose and some 77 hemicelluloses. SDF is considered to have benefits on serum lipids, lowering 
78 the level of serum total cholesterol, while IDF is linked to laxation benefits 79 (Quiles et al., 2016).

80 Several previous studies have investigated reducing the fat in sponge cakes

81 or other bakery products by replacing it with different types of fiber, such as 82 inulin (Rodríguez-García, Salvador, et al., 2014; Zahn et al., 2010), citrus 83 pectin (Lim et al., 2014; Psimouli and Oreopoulou, 2013), peach fiber 84 (Grigelmo-Miguel et al., 2001), cocoa fiber (Martínez-Cervera et al., 2011) or 85 maltodextrin (Psimouli and Oreopoulou, 2013). These studies have found that 86 fat replacement is feasible but affects the batter and cake properties 87 depending on the type of fiber used for the replacement. Moreover, dietary 88 fiber can influence the digestion of starch by reducing the starch breakdown 89 and thus, reducing glucose release and absorption (Brennan, 2005).

90 Dietary fiber incorporated into starch-based foods can entrap starch granules 91 and restrict the availability of water during gelatinization. As a result, the 92 accessibility of starch granules to digestive enzymes is limited under human 93 digestion, which results in the lowering of the glycemic index (Angioloni and 94 Collar, 2011). However, in vitro studies show different results depending on 95 the kind of dietary fiber used.

96 The aim of the present study was to investigate the functionality of soluble 97 and insoluble fibers as replacers for $30 \%$ fat on the formulation of low fat 98 cakes. Maltodextrin was used as soluble dietary fiber and potato fiber was 99 used as insoluble fiber. The batter viscosity was measured and micro-baking 100 was simulated to assess the evolution of air bubble growth. Texture profile 101 analyses were also performed and the crumb structure was examined. 
102 Lastly, the digestibility of the starch was measured through in vitro digestion 103 tests and consumer acceptance was assessed.

104

105

MATERIALS AND METHODS

106

107

\section{Ingredients}

108 Sponge cakes were prepared with the following ingredients: wheat flour 109 (Harinas Segura S.L, Torrente, Valencia, Spain; composition provided by the 110 supplier: $13.5 \%-15.5 \%$ moisture, 9-11\% proteins); white sugar (AB Azucarera 111 Ibérica S.L.U., Madrid, Spain); egg yolk and white, both as pasteurized 112 liquids (Ovocity, Llombay, Valencia, Spain); skimmed milk powder 113 (Corporación Alimentaria Peñasanta, S.A., Siero, Asturias, Spain); refined 114 sunflower oil (Aceites del Sur-Coosur, S.A., Vilches, Jaén, Spain); sodium 115 bicarbonate E-500ii and citric acid E-300 (Sodas y Gaseosas A. Martínez, 116 S.L., Cheste, Valencia, Spain); salt; Fibersol-2, composed of 90\% resistant 117 maltodextrin (Matsutani Chemical Industry Co. Ltd., Hyogo, Japan, total 118 dietary soluble fiber 90\%); Vitacel KF200, a potato fiber-rich food ingredient 119 (J. Rettenmaier and Söhne Gmbh + Co Kg, rich in insoluble fiber (55\%), total 120 dietary fiber 65\%); and distilled water.

\section{Batter and cake preparation}

123 The four formulations studied (Table 1) were the control formulation (C) 124 and three further formulations in which $30 \%$ of the sunflower oil was replaced 125 by a soluble fiber (SF), an insoluble fiber (IF), or a 50/50 mixture of the two 
126 fiber ingredients (M). Extra distilled water was added at ratios of 1:1 Fibersol-

1272 to water and 1:4 Vitacel KF200 to water, as recommended by the suppliers 128 of the fiber ingredients.

129 The batters were prepared using the 'all in' mixing procedure of 130 Rodríguez-García et al (2014), with a few modifications. Firstly, all the liquid 131 ingredients - egg white, yolk, milk and water - were placed in a Kenwood 132 Major Classic mixer (Kenwood, Havant, UK). The solid ingredients - flour, 133 sugar, Fibersol-2 and/or VitacelKF200, bicarbonate of soda, citrus acid and 134 salt - were then added to the same bowl. The last ingredient added was the 135 sunflower oil. To achieve homogeneous batters, all the ingredients were 136 mixed for $30 \mathrm{~s}$ at $202 \mathrm{rpm}$, followed by $1 \mathrm{~min}$ at $260 \mathrm{rpm}$ and $3 \mathrm{~min}$ at 320 $137 \mathrm{rpm}$.

138 To bake each cake, $700 \mathrm{~g}$ of batter were poured into a $20 \mathrm{~cm}$ diameter 139 Pyrex® mold and placed in a conventional oven (Electrolux, model 140 EOC3430DOX, Stockholm, Sweden) that had been preheated to $180^{\circ} \mathrm{C}$ for $14130 \mathrm{~min}$. They were baked at $180^{\circ} \mathrm{C}$ for $47 \mathrm{~min}$. After removing the cakes from 142 the oven, they were left to cool for at least 1 hour and 30 minutes before they 143 were examined. All the batters and cakes were prepared in triplicate and the 144 tests were performed within 24 hours of their preparation.

146 Apparent viscosity

147 Batter viscosity was measured with a Haake Viscotester 6 R Plus 148 viscometer (Thermo Scientific, Walthman, MA), using an R3 spindle at $6 \mathrm{rpm}$ 149 at room temperature. The samples were placed in a thermostatic bath to 
150 maintain a temperature of $25^{\circ} \mathrm{C}$. The measurements were made in duplicate 151 for each batter and in triplicate for each formulation.

152

153 Batter image analysis (micro baking simulation)

154 Microscope observation was performed during the micro baking simulation 155 using a temperature-controlled stage (Analysa-LTS350, Linkam Scientific 156 Instruments Ltd., Surrey, UK) under the lens of a light microscope (Nikon 157 ECLIPSE 80i, Nikon Co. Ltd., Tokyo, Japan). A drop of the sample was 158 placed in the concavity of the glass slide, which was placed on the 159 temperature-controlled stage. During heating, the temperature ramp was 160 controlled by a refrigeration system with a liquid nitrogen pump (Linkam). The 161 temperature profile employed was $1.5^{\circ} \mathrm{C} / \mathrm{min}$ from room temperature $\left(25^{\circ} \mathrm{C}\right)$ 162 to $105^{\circ} \mathrm{C}$. The batter samples were observed at $4 \mathrm{X}$ magnification $(x 4 / 0.13 \infty /-$ 163 WD 17.1 objective lens, Nikon). Photographs were taken with a camera 164 (ExWaveHAD, model DXC-190) fitted to the microscope and connected to a 165 computer. During the micro baking simulation, a video was recorded with 166 photographs taken every $10 \mathrm{~s}$ in a $640 \times 540$ pixel format, using the 167 microscope software (Linksys 32, Linkam). Three samples of each 168 formulation were examined. The images were analyzed with ImageJ software 169 (National Institute of Health, Bethesda, MD).

\section{Macroscopic structure of the crumb}

172 The cakes were cut in half through the center and scanned with an HP 173 Scanjet G2710 (Hewlett-Packard, Palo Alto, CA, U.S.A) at a resolution of 300 
174 dpi. Central sections of cake with a field size of $10 \times 4 \mathrm{~cm}$ were analyzed. The 175 cropped image was split into color channels, the contrast was enhanced and 176 the image was thresholded and binarized with the aid of the ImageJ software 177 program (National Institutes of Health, Bethesda, Maryland, USA). Total cell 178 area within the crumb (\%) and cell size $\left(\mathrm{mm}^{2}\right)$ were calculated. Four images 179 of each formulation were analyzed.

\section{Sponge cake texture}

The textural properties were assessed with a TA-TXTplus texture analyzer (Stable Microsystems, Ltd., Godalming, UK), using the Texture Exponent Lite 32 program (version 6.1.4.0, Stable Microsystems). A texture profile analysis (TPA) was performed on four cubes $(3 \times 3 \times 3 \mathrm{~cm})$ cut from the center of the cake after removing the crust. The cubes were compressed to $40 \%$ of their original height at a test speed of $1 \mathrm{~mm} / \mathrm{s}$ with a $5 \mathrm{~s}$ resting time between the two compression cycles. The trigger force was $5 \mathrm{~g}$. The cubes were compressed with a $5 \mathrm{~cm}$ diameter cylindrical aluminum probe. After the 190 two compression cycles, the following measurements were recorded: hardness, springiness, cohesiveness, chewiness and adhesiveness. 192 Measurements were carried out in duplicate.

\section{Field emission scanning electron microscopy (FESEM)}

195 For each formulation studied, $0.5 \mathrm{~cm}$ sided cubes were cut, frozen at $196-80^{\circ} \mathrm{C}$ and lyophilized (Lyoquest 55, Telstar, Terrassa, Barcelona, España). 197 The samples were then vacuum coated with platinum and observed under a 
198 field emission scanning electron microscope (model Ultra 55 FESEM, Zeiss,

199 Oberkochen, Germany). Each formulation was analyzed in duplicate.

200

201

\section{In vitro digestion}

202

Digestion of the sponge cakes covered three stages: oral, gastric and 203 intestinal.

204 For oral digestion, the protocol described by Smith et al (2015) was 205 followed, with a few modifications. Consequently, $10 \mathrm{~g}$ of cake were 206 crumbled by hand and $3,5 \mathrm{~mL}$ of saliva solution, previously incubated at $20737^{\circ} \mathrm{C}$, were added. This mixture was ground with a blender (Ufesa, 208 U1EBB40001; BP-4500) for $15 \mathrm{~s}$, then $70 \mathrm{~mL}$ of bidistilled water were added 209 and mixed in by hand for $1 \mathrm{~min}$ to simulate mastication. The saliva solution 210 was prepared as described by Mishellany-Dutour et al(2011).The following 211 were dissolved in $1 \mathrm{~L}$ of bidistilled water: $5.208 \mathrm{~g}$ of $\mathrm{NaHCO}_{3}, 1.369 \mathrm{~g}$ of $212 \mathrm{~K}_{2} \mathrm{HPO}_{4} .3 \mathrm{H}_{2} \mathrm{O}, 0.877 \mathrm{~g}$ of $\mathrm{NaCl}, 0.477 \mathrm{~g}$ of $\mathrm{KCl}, 0.441 \mathrm{~g}$ of $\mathrm{CaCl}_{2} .2 \mathrm{H}_{2} \mathrm{O}, 2.16$ $213 \mathrm{~g}$ of mucin from porcine stomach type II (PGM Sigma M2378) and $8.70 \mathrm{~g}$ of a-amylase from porcine pancreas type VI-B (Sigma A3176). orally digested, $25 \mathrm{~g}$ of gastric fluid were placed in the digester, composed of

217 a glass reactor with a thermostat-controlled jacket and continuous magnetic 218 stirring fitted to a controlled temperature water circulator. The gastric fluid 219 was preincubated at $37^{\circ} \mathrm{C}$ for $5 \mathrm{~min}$ at $\mathrm{pH}$ 2. The sample was added to the 220 reactor, the mixture was adjusted to $\mathrm{pH} 2$ with $2 \mathrm{M} \mathrm{HCl}, 0.006 \mathrm{~g}$ of pepsin 221 (Sigma P7000) were added and the mixture was incubated for 1 hour at $37^{\circ} \mathrm{C}$ 
222 with stirring. The electrolyte solution that constituted the gastric fluid was 223 prepared by dissolving the following in $1 \mathrm{~L}$ of distilled water: $3.1 \mathrm{~g}$ of $\mathrm{NaCl}$, $2240.11 \mathrm{~g}$ of $\mathrm{CaCl}_{2}, 1.1 \mathrm{~g}$ of $\mathrm{KCl}, 5.68 \mathrm{~mL}$ of $1 \mathrm{M} \mathrm{NaCO}_{3}$. The $\mathrm{pH}$ was adjusted 225 to 2 with $2 \mathrm{M} \mathrm{HCl}$.

226 For the intestinal stage, the $\mathrm{pH}$ of the sample was raised to 6 with $1 \mathrm{M}$ $227 \mathrm{NaCO}_{3}$ to which pancreatin (Sigma P1750, 4xUSP) and bile salts (Sigma 228 B8631) had been added. The pancreatin and bile salt solution was prepared 229 with $0.1 \mathrm{~g}$ of pancreatin and $0.625 \mathrm{~g}$ of bile salts to $25 \mathrm{~mL}$ of $0.1 \mathrm{M} \mathrm{NaHCO}_{3}$ 230 (Rufián-Henares and Delgado-Andrade, 2009). Amyloglucosidase 231 (A7095 $\geq 300 \mathrm{U} / \mathrm{mL}$, Sigma) was then added at $0.2 \mathrm{~mL} / \mathrm{g}$ of starch in 232 accordance with Oh et al (2014) and Soong et al (2014). The pH was raised 233 to 7.5 with $0.1 \mathrm{M} \mathrm{NaHCO}_{3}$ and the mixture was incubated at $37^{\circ} \mathrm{C}$ for $3 \mathrm{~h}$ with 234 stirring. Aliquots were removed at $0,20,60,90,120$ and $180 \mathrm{~min}$ of 235 digestion, immediately adding $1.4 \mathrm{~mL}$ of ethanol to stop the reaction (Bae et 236 al., 2013), and centrifuged at $3000 \mathrm{rpm}$ for $3 \mathrm{~min}$. The glucose concentration 237 was then measured with the GOPOD assay kit at $510 \mathrm{~nm}$. For this 238 measurement, $0.1 \mathrm{~mL}$ aliquots of the supernatant were taken, $3 \mathrm{~mL}$ of the 239 GOPOD reagent were added, the sample was incubated at $40-50^{\circ} \mathrm{C}$ for 20 240 minutes and the absorbance was read at $510 \mathrm{~nm}$.

241 The experimental data were fitted to the first-order equation proposed by 242 Goñi et al (1997) $\left[C=C_{\infty}\left(1-e^{-k t}\right)\right]$, where $C$ is the concentration at $t$ time, $C_{\infty}$ is 243 the equilibrium concentration, $k$ is the kinetic constant and $t$ is the chosen 244 time. 


\section{Sensory Analysis \\ 247 Consumers were recruited among students and employees of the Universitat \\ 248 Politècnica de València. A total of 82 untrained panelists (consumers) aged \\ 249 22-63, were used for the study. Of the participants, 49\% were women and \\ $25051 \%$ men. \\ 251 The samples were assessed in a standardized tasting room equipped with 252 individual booths. Each consumer received four pieces of cakes (C, SF, M 253 and IF) coded by three digit random numbers. The pieces of cakes were 254 served at room temperature in random order. Water was supplied to clean the 255 consumers' mouths between each sample. \\ 256 Consumer acceptance testing was done using a 9-box structured hedonic 257 scale to score the "appearance", "texture", "taste" acceptability and "overall 258 acceptance" of the product (from 1= "I dislike it extremely" to $9=$ "I like it 259 extremely"). \\ 260}

261 Statistical analysis

262 Analysis of variance (ANOVA) was used for statistical analysis of the 263 results. The least significant differences (LSD) were calculated with a 264 significance level of $p<0.05$. The Statgraphics Centurion XVI.II statistical 265 program (StatPoint Technologies, Inc., Warrenton, VA, USA) was used for 266 this purpose.

267

268 RESULTS AND DISCUSSION

269 


\section{Apparent viscosity}

271

The batter viscosity results for the sponge cake formulations studied

272 are expressed in mPa.s. On reducing the fat content by $30 \%$, a significant

$273(p<0.05)$ reduction was observed in the viscosity of the IF $(7675.27 \pm 53.53)$

274 and $\mathrm{M}(9032.95 \pm 233.36)$ batters in comparison to the control (10732.04 \pm

275 348.42), however no significant $(p>0.05)$ difference was observed between

276 SF (10724.73 \pm 470.06) and control batters. This tendency has previously

277 been reported by other authors (Rodríguez-García, Salvador, et al., 2014;

278 Román et al., 2015; Zahn et al., 2010) who also obtained low viscosity values

279 on replacing fat with soluble fibers and functional ingredients and lower

280 viscosity values at higher rates of replacement.

281 Bearing in mind that the fat reduction level was constant in the present 282 study, the ingredient with insoluble fiber led to the greatest reduction in 283 viscosity, This rheological behavior is largely due to the greater quantity of 284 water added to the insoluble fiber formulation (1:4) compared to the batter 285 with soluble fiber (1:1), giving IF a higher ratio of liquid to solid ingredients, 286 which led to lower viscosity values.

288 Light microscopy and image analysis of the batters

289 Figure 1A shows images of the batters of the different formulations (C, $290 \mathrm{SF}, \mathrm{M}$ and IF) at different temperatures $\left(30,60,90\right.$ and $\left.100^{\circ} \mathrm{C}\right)$ during micro 291 baking simulation.

292 Visual examination of the batter images showed a clear air bubble 293 expansion effect due to the lower fat content and the addition of soluble and 
294 insoluble fibers together with water. In batter C, the size of the bubbles 295 increased in a uniform, controlled way, distributing the bubbles evenly as the 296 temperature rose.

297 In general, the reduction in fat and the addition of soluble and insoluble 298 fibers allowed more bubbles to be incorporated during the mixing process 299 (Figs. 1A and 1B). As the temperature rose, the bubbles naturally expanded. 300 Bubble expansion was higher in the IF batter, which were the least stable at 301 rising temperatures, with some of the bubbles losing their identity at $100^{\circ} \mathrm{C}$ 302 as they coalesced with neighboring bubbles.

303 The images were analyzed to quantify the bubble size distribution during 304 micro baking. Figure 1B presents histograms of the bubble size distributions 305 at different temperatures. The C formulation batter incorporated fewer 306 bubbles (Fig 1B) and showed a tendency to regular distribution of bubble 307 sizes during heating, compared to the other batters. This behavior could be 308 due to the greater apparent viscosity of this batter (C), which would help to 309 make the air bubbles more stable, delaying their movement through the 310 batter and slowing down their disproportionate growth and coalescence as 311 observed previously by Rodríguez-García, Salvador, et al., 2014).

312 In general, a lower apparent viscosity of the replaced batters (SF, M and 313 IF) may have allowed occluding more air during mixing; so, more number of 314 bubbles per field is observed at the beginning of the micro baking process, 315 particularly in the case of batters SF and M. During the micro baking process 316 the air bubble sizes acquired an irregular distribution but towards the end of 
317 the heating scale (at $90^{\circ} \mathrm{C}$ and $100^{\circ} \mathrm{C}$ ), the IF batter was found to have a 318 higher percentage of larger bubbles.

319 The considerable reduction in the apparent viscosity of the IF batters and 320 resulting reduction of air bubble stability in these samples increased the 321 mobility, disproportion ratio, coalescence and size of the bubbles.

323 Macroscopic structure of the crumb

324 Figure 2 shows scanned, contrasted and binarized images of the different 325 cakes (C, SF, M and IF).

326 Visual analysis of these cake images shows a practically uniform crumb 327 macrostructure in the control cake (C). In contrast, a series of diffusion 328 pathways appeared in the crumb of the reduced-fat sponge cakes. These 329 pathways were less noticeable in the SF cake and more noticeable and 330 numerous in the IF cake.

331 The images of the cakes were also analyzed to quantify the crumb 332 macrostructure results (table 2$)$. IF presented a significantly $(p<0.05)$ higher 333 cell size and a higher total cell area values compared to the other cakes. 334 Consequently, IF presented a more aerated structure with bigger cells. These 335 results agree with the tendency observed in the sponge cake batters during 336 micro baking, as described in the previous section- IF batter was found to 337 have a higher amount of larger bubbles at the end of the micro baking-. In 338 turn, this is intrinsically affected by viscosity; thus, in IF crumb cake the rising 339 percentage of air would be directly related to the low viscosity found in IF 340 batter. Changes in the thermosetting mechanism, as a consequence of the 
341 extra water added, could also be responsible for the presence of the diffusion 342 path ways in replaced cakes.

\section{Cake texture}

345 The results of the parameters obtained from the texture profile analysis 346 curves for the sponge cakes under study are presented in Table 2.

347 The $30 \%$ fat reduction with fiber generated significantly $(p<0.05)$ higher 348 hardness values in SF, M and IF samples. IF was the hardest of the samples. 349 Hardness values followed the trend $\mathrm{IF}>\mathrm{M}>\mathrm{SF}$, and significant differences 350 were observed among all of them This means that more force was required 351 to compress the IF cake than the other formulations. Eslava-Zomeño et al 352 (2016) obtained significantly higher hardness values for sponge cakes made 353 with Optisol $^{\mathrm{TM}} 5300$ at different fat replacement ratios. Psimouli and 354 Oreopoulou (2013) also found significantly higher hardness values in sponge 355 cakes prepared with different carbohydrates as fat replacers..

356 The chewiness values showed a similar trend. The chewiness values of 357 the control cake were significantly lower $(p<0.05)$ than those of the other 358 sponge cakes. When $30 \%$ of the fat was replaced by adding soluble and/or 359 insoluble fibers to the formulations, chewiness increased significantly $360(p<0.05)$. IF was the chewiest cake. This means that greater energy was 361 needed to chew the IF cake enough to be swallowable.

362 In general, the tendency for these parameters to increase could be related 363 to the reduction in the batter viscosity of the respective formulations. In the 364 control formulation batter, both the low number of bubbles and the 
365 distribution and homogeneous expansion of small bubbles influenced its low 366 hardness values. In contrast, the greater variation in bubble size observed on 367 adding the soluble and insoluble fibers, particularly the latter, increased the 368 cake hardness considerably. Also, bearing in mind that one of the functions 369 of fat is to make cakes smooth and soft, reducing the fat and adding soluble 370 and insoluble fibers could be expected to increase the hardness of the cakes 371 and, consequently, their chewiness.

372 The cohesiveness and adhesiveness values showed no significant $373(p>0.05)$ differences between the sponge cakes studied. The lower fat 374 content and addition of soluble and insoluble fibers did not influence the work 375 needed to compress the samples a second time compared to the first, nor did 376 they alter the work needed to detach the compression probe from the 377 sample.

378 The springiness values showed no significant $(p>0.05)$ differences 379 between $\mathrm{C}$ and SF or between $\mathrm{M}$ and IF, though the latter pair presented 380 significantly $(p>0.05)$ higher springiness.

381 The use of insoluble fiber in the formulation of the cakes seems to 382 influence in the texture parameters as IF cake is the one with highest 383 hardness, chewiness and springiness values.

385 Field emission scanning electron microscopy (FESEM)

386 The microstructure of the soluble fibers (Fibersol-2), insoluble fibers 387 (Vitacel K200) and C, SF and IF cakes can be seen in the images obtained 
388 through field emission scanning electron microscopy (FESEM), shown in 389 Figure 3.

390 The fibers showed considerable differences in structure. The soluble fiber 391 was made up of numerous particles of varying sizes and shapes, although 392 most were granular and presented a smooth appearance. The insoluble fiber 393 had the typical rough appearance of plant cells, with visible cell walls 394 (labelled pc) and transport tissues (labelled vc).

395 The structure of the control cake (C) can be seen to be composed of a 396 gluten network, formed by the flour, which contained the other ingredients. 397 The partially gelled starch granules were embedded in the gluten network 398 and the oil acted as a lubricant, creating a continuous structure. The 399 structures of the SF and IF cakes, with a $30 \%$ reduction in fat, were 400 influenced by the characteristics of the respective fibers and presented a 401 more irregular microstructure, since there was a smaller coating of oil. In the 402 SF cakes, the partially gelled starch granules distributed irregularly through 403 the cake matrix were very evident, as they retained their identity. In the IF 404 cakes, the starch granules were deeply embedded in the matrix, giving rise to 405 a more compact structure that can be related to their harder texture.

\section{In vitro digestion}

408 Figure 4 shows the digestibility curves of cakes C, SF and IF after in vitro 409 digestion. No significant $(p>0.05)$ differences were observed between the 410 samples at $20,60,90$ and 120 minutes of digestion. However, SF presented 411 significantly $(p<0.05)$ lower values than the other cakes after 180 minutes. 
412 The parameters obtained after fitting the curves using the first order model 413 described by Goñi et al (1997) are shown in Table 3. Although the kinetic 414 constant (k), which indicates the rate of starch hydrolysis is augmented, it 415 can be observed that the area under the hydrolysis curve after 180 min (AUC $416180)$ and the equilibrium concentration $\left(\mathrm{C}^{\infty}\right)$ values were the lowest for $\mathrm{SF}$, 417 being significant $(p<0.05)$ for $C_{\infty}$ values. AUC 180 is a comprehensive 418 parameter for the starch hydrolysis, relating the glucose release over a 419 hydrolysis period of $180 \mathrm{~min}$ (Gularte et al., 2012) and $\mathrm{C}_{\infty}$ indicates the 420 concentration at the equilibrium point, and a higher concentration of final 421 product reflects increased digestibility of starch (Dura et al., 2014). Taking 422 into account the results obtained for AUC 180 and $C \infty$ values, the use of 423 soluble fiber in the formulation of the cake would result in lower glucose 424 release under in vitro conditions. This could be related to the field emission 425 scanning electron microscope (FESEM) images, where the starch granules in 426 the SF cake matrix were observed to be less gelled than those of the IF cake. 427 Moreover, the soluble fiber with greater water absorption capacity would 428 compete with the starch for the available water during sponge cake 429 processing, leading to low starch gelatinization and consequently reducing 430 the release of glucose during in vitro digestion in the case of SF cake.

\section{Sensory acceptance}

433 Table 4 presents the mean liking scores for the "appearance", "texture", 434 "taste" and "overall acceptance" of the control cake and the cakes with the 435 different type of fibers. 
436 Statistical analysis showed that the control cake $(C)$ and the cakes where fat 437 was replaced by soluble fiber (SF) and the mix of fibers (M) did not differ 438 significantly $(P<0.05)$ in all the attributes. However, IF cake obtained the 439 lowest value when all the attributes were scored; being significantly $(P<$ 440 0.05) lower than the other three samples for "texture" and "overall 441 acceptance" attributes.

442 These results revealed that quality differences due to fat replacement by 443 soluble fiber or by the mix of fibers were not perceived by consumers. 444 However, the replacement by insoluble fiber gave place to significantly $(P<$ 445 0.05) lower scores for "texture" and "overall acceptance" attributes. If the 446 texture hedonic results are compared with the instrumental measurements it 447 can be observed that the highest hardness and chewiness may have had an 448 important negative influence in hedonic acceptability. In this context, IF was 449 the hardest of the samples but its texture was the less liked by consumers.

\section{CONCLUSIONS}

453 Replacing $30 \%$ of the fat in a sponge cake formulation with ingredients 454 that are rich in insoluble fiber and extra water caused a reduction in viscosity. 455 As a result of their low viscosity, the batters with insoluble fiber incorporated 456 a greater quantity of air bubbles during mixing, as observed in microbaking, 457 and IF batter presented larger bubble size than the other formulations at the 458 same temperatures. In the macroscopic analysis of the crumb, the IF cake 459 also showed a larger quantity of diffusion pathways and a greater percentage 
460 of air. Replacing $30 \%$ of the fat in the sponge cake formulation with 461 ingredients that are rich in soluble and/or insoluble fiber also caused 462 increased hardness and chewiness. The IF cake was spongier because it 463 contained a greater quantity of air but was also harder, which is related to the 464 more compact matrix observed by FESEM. During in vitro digestion, SF 465 showed a lower glucose release at 180 minutes. Regarding the sensory 466 acceptance, the consumers did not find differences among C, SF and M 467 cakes, however, IF cake was the less liked by consumers. Overall, 468 considering the physicochemical, sensory and nutritional quality, soluble fiber 469 may be used for partial replacement of fat in sponge cake formulations and 470 constitutes an appropriate strategy for obtaining healthy sponge cakes.

\section{ACKNOWLEDGMENTS}

473 The authors are grateful to INIA for financial support through the 474 BERRYPOM - Adding value to fruit processing waste: innovative ways to 475 incorporate fibers from berry pomace in baked and extruded cereal-based 476 foods project, included in the ERA-NET - SUSFOOD program.

477 They also wish to thank Mary Georgina Hardinge for English translation 478 and copyediting assistance. 


\section{References}

481 Angioloni A and Collar C (2011) Physicochemical and nutritional properties of 482 reduced-caloric density high-fibre breads. LWT - Food Science and 483 Technology, Elsevier Ltd 44(3): 747-758.

484 Bae IY, Lee HI, Ko A, et al. (2013) Substituting whole grain flour for wheat 485 flour: Impact on cake quality and glycemic index. Food Science and 486 Biotechnology 22(5): 1-7.

487 Brennan CS (2005) Dietary fibre, glycaemic response, and diabetes. $488 \quad$ Molecular Nutrition and Food Research 49(6): 560-570.

Dura A, Błaszczak W and Rosell CM (2014) Functionality of porous starch 490 obtained by amylase or amyloglucosidase treatments. Carbohydrate $491 \quad$ Polymers 101: 837-845.

492 Eslava-Zomeño C, Quiles A and Hernando I (2016) Designing a clean label 493 sponge cake with reduced fat content. Journal of food science 81(10): C2352-C2359.

495 Goñi I, Garcia-Alonso A and Saura-Calixto F (1997) A starch hydrolysis 496 procedure to estimate glycemic index. Nutrition Research, Elsevier 17(3): 427-437.

498 Grigelmo-Miguel N, Carreras-Boladeras E and Martín-Belloso O (2001) 499 Influence of the addition of peach dietary fiber in composition, physical 500 properties and acceptability of reduced-fat muffins. Food Science and $501 \quad$ Technology International 7: 425-431.

502 Gularte MA, Gómez M and Rosell CM (2012) Impact of legume flours on 503 quality and in vitro digestibility of starch and protein from gluten-free 
504

505

506

507

508

509

510

511

512

513

514

515

516

517

518

519

520

521

522

523

524

525

526

527

cakes. Food and Bioprocess Technology 5(8): 3142-3150.

Hardacre AK, Yap SY, Lentle RG, et al. (2015) The effect of fibre and gelatinised starch type on amylolysis and apparent viscosity during in vitro digestion at a physiological shear rate. Carbohydrate Polymers, Elsevier Ltd. 123: 80-88.

Kratz M, Baars T and Guyenet S (2013) The relationship between high-fat dairy consumption and obesity, cardiovascular, and metabolic disease. European Journal of Nutrition 52(1): 1-24.

Lim J, Ko S and Lee S (2014) Use of Yuja (Citrus junos) pectin as a fat replacer in baked foods. Food Science and Biotechnology 23(6): 18371841.

Martínez-Cervera S, Salvador A, Muguerza B, et al. (2011) Cocoa fibre and its application as a fat replacer in chocolate muffins. LWT - Food Science and Technology 44(3): 729-736.

Martínez-Cervera S, Sanz T, Salvador A, et al. (2012) Rheological, textural and sensorial properties of low-sucrose muffins reformulated with sucralose/polydextrose. LWT - Food Science and Technology, Elsevier Ltd 45(2): 213-220.

Matsakidou A, Blekas G and Paraskevopoulou A (2010) Aroma and physical characteristics of cakes prepared by replacing margarine with extra virgin olive oil. LWT - Food Science and Technology, Elsevier Ltd 43(6): 949-957.

Mente A., De Koning L., Shannon HS., et al. (2009) A systematic review of the evidence supporting a causal link between dietary factors and 

coronary heart disease. Archives of Internal Medicine 169(7): 659-669.

529

530

531

532

533

534

535

536

537

538
Mishellany-Dutour A, Peyron MA, Croze J, et al. (2011) Comparison of food boluses prepared in vivo and by the AM2 mastication simulator. Food Quality and Preference, Elsevier Ltd 22(4): 326-331.

Oh IK, Bae IY and Lee HG (2014) In vitro starch digestion and cake quality: Impact of the ratio of soluble and insoluble dietary fiber. International Journal of Biological Macromolecules, Elsevier B.V. 63: 98-103.

Psimouli V and Oreopoulou V (2013) The effect of fat replacers on batter and cake properties. Journal of Food Science 78(10): 1495-1502.

Quiles A, Campbell GM, Struck S, et al. (2016) Fiber from fruit pomace: A review of applications in cereal-based products. Food Reviews International in press.

Rodríguez-García J, Puig A, Salvador A, et al. (2012) Optimization of a sponge cake formulation with inulin as fat replacer: structure, physicochemical, and sensory properties. Journal of Food Science, Blackwell Publishing Inc 77(2): C189-C197.

Rodríguez-García J, Sahi SS and Hernando I (2014) Optimizing mixing during the sponge cake manufacturing process. Cereal Foods World, American Association of Cereal Chemists 59(6): 287-292.

Rodríguez-García J, Salvador A and Hernando I (2014) Replacing fat and sugar with inulin in cakes: bubble size distribution, physical and sensory properties. Food and Bioprocess Technology 7(4): 964-974.

Román L, Santos I, Martínez MM, et al. (2015) Effect of extruded wheat flour as a fat replacer on batter characteristics and cake quality. Journal of 
552

553

554

555

556

557

558

559

560

561

562

563

564

565

566

567

568

569

570

571

572

573

Food Science and Technology 52(12): 8188-8195.

Rufián-Henares JA and Delgado-Andrade C (2009) Effect of digestive process on Maillard reaction indexes and antioxidant properties of breakfast cereals. Food Research International, Elsevier Ltd 42(3): 394400.

Smith F, Pan X, Bellido V, et al. (2015) Digestibility of gluten proteins is reduced by baking and enhanced by starch digestion. Molecular Nutrition and Food Research 59(10): 2034-2043.

Soong YY, Tan SP, Leong LP, et al. (2014) Total antioxidant capacity and starch digestibility of muffins baked with rice, wheat, oat, corn and barley flour. Food Chemistry, Elsevier Ltd 164: 462-469.

United Nations Food and Agriculture Organization (FAO) (n.d.). Available from: www.fao.org/nutrition/en/.

Viebke C, Al-Assaf S and Phillips GO (2014) Food hydrocolloids and health claims. Bioactive Carbohydrates. Diet Fibre 4: 101-104.

World Health Organization (WHO) (n.d.). Available from: http://www.who.int/dietphysicalactivity/publications/trs916/en/.

Zahn S, Pepke F and Rohm H (2010) Effect of inulin as a fat replacer on texture and sensory properties of muffins. International Journal of Food Science and Technology 45(12): 2531-2537. 
574 Table 1. Composition of the formulations studied (\% flour base)

575

\begin{tabular}{lllll}
\hline Ingredient* & C & SF & M & IF \\
\hline Flour & 100 & 100 & 100 & 100 \\
Sugar & 100 & 100 & 100 & 100 \\
Egg yolk & 27 & 27 & 27 & 27 \\
Egg white & 54 & 54 & 54 & 54 \\
Milk & 50 & 50 & 50 & 50 \\
Oil & 46 & 32.2 & 32.2 & 32.2 \\
Soluble fibre & 0 & 4 & 2 & 0 \\
Insoluble fibre & 0 & 0 & 2 & 4 \\
Water & 0 & 4 & 10 & 16 \\
Sodium & & & 4.5 & 4 \\
Bicarbonate & 4 & 4 & 4 & 3 \\
Citric acid & 3 & 3 & 1.5 & \\
Salt & 1.5 & 1.5 & & \\
\hline
\end{tabular}

576

577 C: control cake; SF: cake with soluble fibre; M: cake with a mixture of soluble and insoluble

578 fibre; IF: cake with insoluble fibre

579 
580

581

582 Table 2. Macroscopic structure of the crumb and textural properties of the cakes.

\begin{tabular}{|c|c|c|c|c|c|c|c|}
\hline \multirow[b]{2}{*}{ Sample } & \multicolumn{2}{|c|}{ Crumb Structure } & \multicolumn{5}{|c|}{ Cake Texture } \\
\hline & $\begin{array}{c}\text { Cell Size } \\
\left(\mathrm{mm}^{2}\right)\end{array}$ & $\begin{array}{l}\text { Total Cell } \\
\text { Area }(\%)\end{array}$ & $\begin{array}{c}\text { Hardness } \\
\text { (N) }\end{array}$ & $\begin{array}{c}\text { Chewiness } \\
(\mathrm{N})\end{array}$ & Cohesiveness & Springiness & $\begin{array}{c}\text { Adhesiveness } \\
\text { (g.s) }\end{array}$ \\
\hline C & $1.0^{\mathrm{a}}(0.1)$ & $28.13^{\mathrm{a}}(2.37)$ & $4.98^{\mathrm{a}}(0.46)$ & $3.15^{\mathrm{a}}(0.28)$ & $0.71^{\mathrm{a}}(0.01)$ & $0.88^{\mathrm{a}}(0.01)$ & $2.55^{\mathrm{a}}(1.55)$ \\
\hline SF & $1.0^{\mathrm{a}}(0.2)$ & $30.27^{\mathrm{a}}(4.65)$ & $5.62^{\mathrm{b}}(0.41)$ & $3.57^{\mathrm{b}}(0.22)$ & $0.72^{\mathrm{a}}(0.01)$ & $0.88^{\mathrm{a}}(0.01)$ & $3.17^{\mathrm{a}}(1.01)$ \\
\hline$M$ & $1.1^{\mathrm{a}}(0.1)$ & $32.45^{\mathrm{a}}(2.11)$ & $6.22^{c}(0.82)$ & $3.98^{\mathrm{c}}(0.49)$ & $0.72^{\mathrm{a}}(0.00)$ & $0.89^{\mathrm{b}}(0.01)$ & $2.82^{\mathrm{a}}(2.01)$ \\
\hline IF & $1.4^{\mathrm{b}}(0.2)$ & $38.52^{\mathrm{b}}(3.69)$ & $6.95^{\mathrm{d}}(0.69)$ & $4.46^{\mathrm{d}}(0.43)$ & $0.72^{\mathrm{a}}(0.00)$ & $0.90^{\mathrm{b}}(0.01)$ & $2.73^{\mathrm{a}}(1.12)$ \\
\hline
\end{tabular}

Figures8ih brackets are standard deviations. ${ }^{a, b, c, d}$ Means with different letters in the same column differ significantly $(p<0.05)$. C: ContrbB5ake, FS: cake with soluble fibre; M: cake with a mixture of soluble and insoluble fibre; Fl: cake with insoluble fibre.

586 
3

4

5

6

7

8

9

10

11

12

13

14

15

16

17

18

19

20

21
587

588

Table 3. Kinetics of the in vitro starch digestibility.

\begin{tabular}{cccc} 
Sample & AUC 180 & Co & $k$ \\
\cline { 2 - 3 } & & $(\mathrm{g} / 100)$ & $\left(\mathrm{min}^{-1}\right)$ \\
\hline $\mathrm{C}$ & $2075.7^{\mathrm{a}}(15.6)$ & $14.1^{\mathrm{a}}(0.4)$ & $0.030^{\mathrm{a}}(0.003)$ \\
$\mathrm{SF}$ & $1794.1^{\mathrm{a}}(279.3)$ & $11.6^{\mathrm{b}}(1.5)$ & $0.039^{\mathrm{a}}(0.007)$ \\
IF & $1971.6^{\mathrm{a}}(64.6)$ & $13.1^{\mathrm{a}}(0.3)$ & $0.033^{\mathrm{a}}(0.001)$
\end{tabular}

Value $58 \mathrm{~g}$ brackets are standard deviations

Means with different letters in the same column differ significantly $(p<0.05)$.

C: Co590I cake, SF: cake with soluble fibre; M: cake with a mixture of soluble and insoluble fibre; IF: cake with insoluble fibre. 
592 Table 4. Liking for appearance, texture, taste and overall

593 acceptance of cakes.

\begin{tabular}{|c|c|c|c|c|}
\hline Sample & Appearance & Texture & Taste & Overall acceptance \\
\hline C & $7.00^{\mathrm{a}}$ & $6.90^{\mathrm{a}}$ & $7.00^{\mathrm{a}}$ & $7.15^{\mathrm{a}}$ \\
\hline SF & $6.93^{a, b}$ & $6.78^{\mathrm{a}}$ & $6.91^{a, b}$ & $7.04^{\mathrm{a}}$ \\
\hline M & $6.80^{a, b}$ & $6.73^{\mathrm{a}}$ & $6.90^{\mathrm{a}, \mathrm{b}}$ & $7.03^{\mathrm{a}}$ \\
\hline IF & $7.03^{\mathrm{b}}$ & $6.18^{\mathrm{b}}$ & $6.46^{\mathrm{b}}$ & $6.53^{\mathrm{b}}$ \\
\hline $\begin{array}{l}\text { Values are } \\
\text { differ signifi }\end{array}$ & $\begin{array}{l}\text { 2). }{ }^{a, b, c, d} M \\
05) . C: C o n\end{array}$ & ith diffe & t letters & $\begin{array}{l}\text { n the same column } \\
\text { luble fibre; } M \text { : cake }\end{array}$ \\
\hline
\end{tabular}

596 with a mixture of soluble and insoluble fibre; IF: cake with insoluble fibre. 

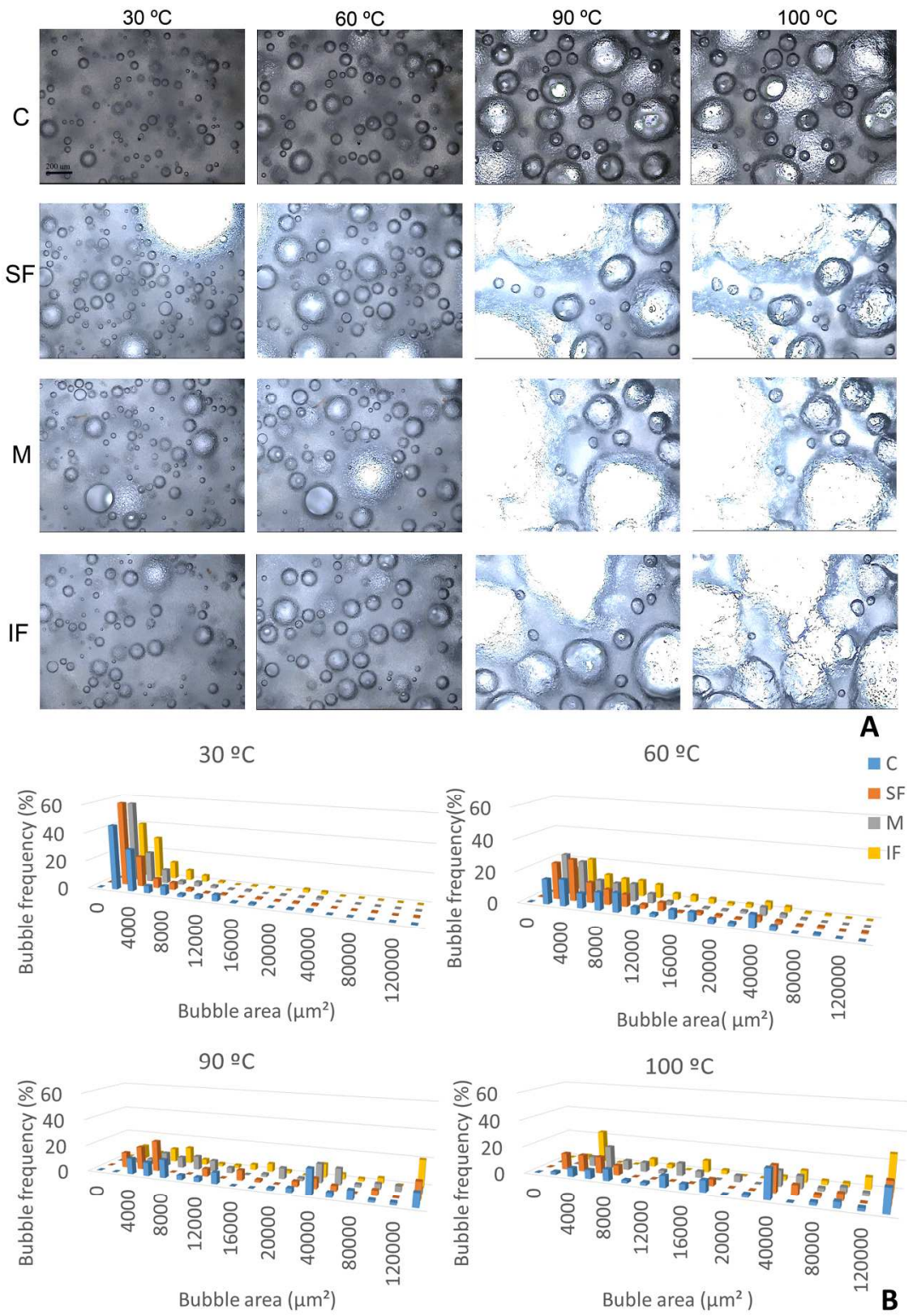

FIGURE 1. A: Light microscopy images of bubble expansion at different temperatures during microbaking. C: control cake; SF: sponge cake with soluble fiber; $\mathrm{M}$ : sponge cake with a mixture of soluble and insoluble fiber; IF: sponge cake with insoluble fiber. B: Histograms of bubble size distribution. C: blue, SF: orange, M: grey, IF: yellow.

$175 \times 250 \mathrm{~mm}(300 \times 300 \mathrm{DPI})$ 

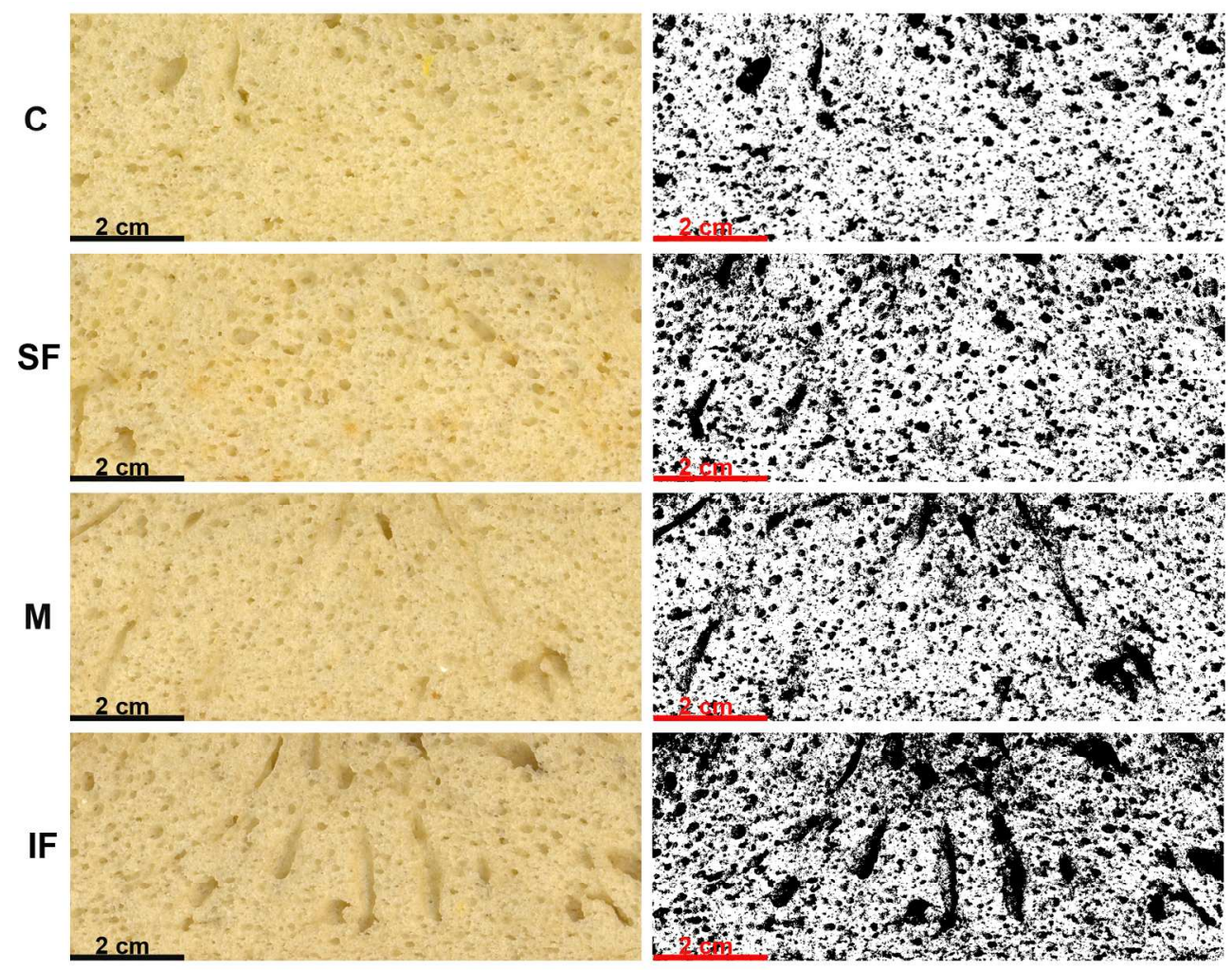

FIGURE 2. A: Scanned images of C, SF, M and IF sponge cakes, field size $4 \times 10 \mathrm{~cm}$, and corresponding binarised images (118 pixels/cm). C: control cake; SF: sponge cake with soluble fiber; M: sponge cake with a mixture of soluble and insoluble fiber; IF: sponge cake with insoluble fiber

$175 \times 142 \mathrm{~mm}(300 \times 300 \mathrm{DPI})$ 
FIGURE 3. Field emission scanning electron microscopy (FESEM). Images of soluble fiber (Fibersol-2) and insoluble fiber (Vitacel KF200), magnification 100x, bar $=100 \mu \mathrm{m}$. Images of cakes C, SF and IF, magnification $250 \mathrm{x}$, bar $=20 \mu \mathrm{m}$. pc: cell walls, vc: transport tissues. C: control cake; SF: sponge cake with soluble fiber; IF: sponge cake with insoluble fiber.

$399 \times 299 \mathrm{~mm}(300 \times 300 \mathrm{DPI})$ 


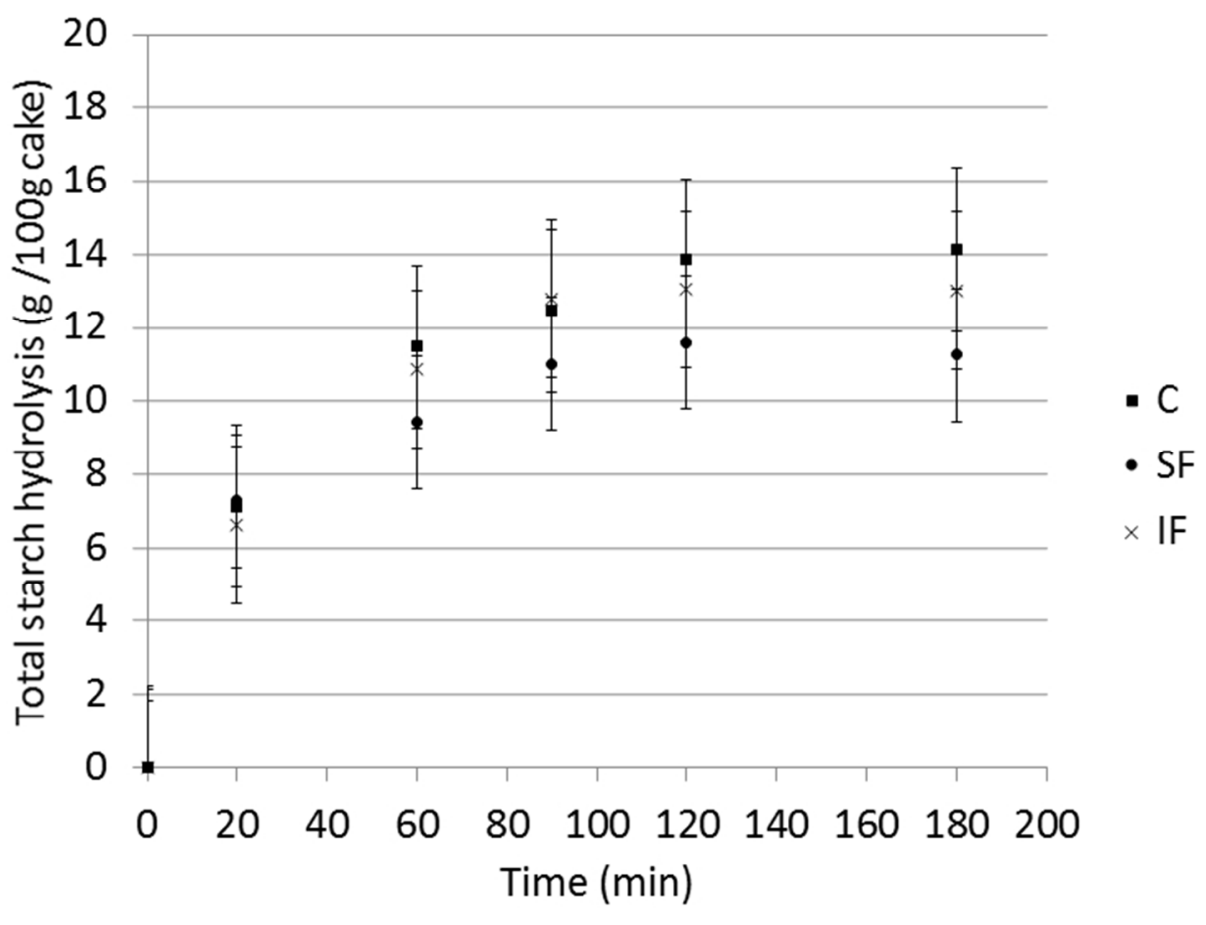

FIGURE 4. In vitro digestibility of starch of the cakes C, SF, M and IF. C: control cake; SF: sponge cake with soluble fiber; $\mathrm{M}$ : sponge cake with a mixture of soluble and insoluble fiber; FI: sponge cake with insoluble fiber.

$210 \times 170 \mathrm{~mm}(96 \times 96$ DPI) 


\section{SAGE AUTHORSHIP CHANGE REQUEST}

\section{INSTRUCTIONS:}

Please print and complete all sections of this form. We require that all authors (including current coauthors, those to be added and those to be removed) sign the relevant sections below. Once complete, please email the form back to sender.

\section{SECTION ONE: PAPER INFORMATION}

\begin{tabular}{|l|l|l|}
\hline JOURNAL NAME & \multicolumn{2}{|c|}{ FOOD SCIENCE AND TECHNOLOGY INTERNATIONAL } \\
\hline PAPER TITLE & MANUSCRIPT ID NUMBER \\
\hline USING DIFERENT FIBERS TO REPLACE FA IN SPONGE CAKES. IN VITRO STARCH DIGESTION AND PHYSICO-STRUCTURA STUDIES & FSTI-18-0029.R1 \\
\hline
\end{tabular}

\section{SECTION TWO: ESSENTIAL CONDITIONS FOR CHANGE}

The new author list should contain only those who can legitimately claim authorship. This is all those who:

1) Have made a substantial contribution to the concept and design, acquisition of data or analysis and interpretation of data; AND

2) Drafted the article or revised it critically for important intellectual content; AND

3) Approved the version to be published.

NB: Registered authors should meet the conditions of all of the points above. All contributors who do not meet the criteria for authorship should instead be listed in an 'Acknowledgements' section.

\section{SECTION THREE: REASON FOR AUTHORSHIP CHANGE}

Please provide a detailed explanation for the change in authors in the box below.

Elena Diez-Sánchez has made a substantial contribution to the design, acquisition and interpretation of data in the sections of the manuscript corresponding to digestion in vitro and sensory studies. She revised the manuscript and approved the version to be published. 


\section{SECTION FOUR: AUTHOR DECLARATIONS}

We agree to the proposed change of authorship to the above paper. NB: all authors (added and removed) must sign below

DECLARATION: All the below listed authors agree that they can claim authorship to the submitted paper as they meet the criteria of the points listed in SECTION TWO.

\begin{tabular}{|c|c|c|}
\hline $\begin{array}{l}\text { List of existing and proposed new authc } \\
\text { proposed change. The individuals listed } \\
\text { (Please add additional rows if required. }\end{array}$ & $\begin{array}{l}\text { sign. Please sign, } \\
\text { will each be cre }\end{array}$ & $\begin{array}{l}\text { the } \\
\text { hed paper. }\end{array}$ \\
\hline Author name & Author signature & \begin{tabular}{|l|} 
Date \\
\end{tabular} \\
\hline Elena Diez-Sánchez & Byel & $5 / 3 / 18$ \\
\hline & & \\
\hline & & \\
\hline & & \\
\hline & & \\
\hline
\end{tabular}

DECLARATION: All the below listed authors agree that they cannot claim authorship to the submitted paper as they do not (or no longer) meet the criteria of the points listed in SECTION TWO.

\begin{tabular}{|l|l|l|}
\hline $\begin{array}{l}\text { List of removed authors. Please sign, indicating your agreement to be removed from the list of } \\
\text { registered authors. The individuals listed below will not be credited as authors in the published paper. } \\
\text { (Please add additional rows if required.) }\end{array}$ & Author signature & Date \\
\hline Author name & & \\
\hline & & \\
\hline & & \\
\hline
\end{tabular}

